\title{
O juízo de crianças sobre a possibilidade de amar um amigo, um inimigo e um desconhecido
}

The judgment of children on the possibility of loving a friend, an enemy and a stranger

El juicio de los niños sobre la posibilidad de amar a un amigo, un enemigo y un desconocido

\author{
Ariadne Dettmann Alves* \\ Heloisa Moulin de Alencar ${ }^{* *}$ \\ Antonio Carlos Ortega ${ }^{* * *}$
}

\begin{abstract}
Resumo
Este trabalho tem por objetivo explorar a influência do vínculo (amigo e inimigo) ou sua ausência (desconhecido) na concepção de amor de crianças. Entrevistamos, individualmente, 40 escolares (6 e 9 anos) sobre a possibilidade de uma criança amar um amigo, inimigo e desconhecido, utilizando o método clínico. A maioria dos participantes afirmou ser possível amar um amigo, ressaltando a amizade. Entretanto poucos concordaram com a possibilidade quanto ao inimigo, e argumentaram principalmente devido à ação negativa dessa pessoa. Um número ainda menor considerou ser possível amar o desconhecido, justificando pela ausência do vínculo. Apesar de poucos terem afirmado a possibilidade de amar um inimigo, constatamos que o número aumentou com a idade, o que pode indicar uma gênese dessa concepção de amor. Este trabalho pode contribuir para a ampliação dos estudos na área da moralidade, fornecendo subsídios teóricos para auxiliar práticas de educação em valores morais.
\end{abstract}

Palavras-chave: Desenvolvimento moral. Virtudes. Amor. Vínculos. Crianças.

\footnotetext{
Abstract

This paper aims to explore the influence of the bond (friend and enemy) or its absence (stranger) in the conception of a child's love. We interviewed individually, 40 school children (6 and 9) on the possibility of a child

Texto recebido em julho de 2012 e aprovado para publicação em setembro de 2014.

Este estudo faz parte da dissertação de mestrado da primeira autora, sob orientação da segunda e coorientação do terceiro. Os autores agradecem o apoio financeiro da Coordenação de Aperfeiçoamento de Pessoal de Nível Superior (CAPES) e a todos aqueles que participaram da pesquisa.

*Mestra pelo Programa de Pós-Graduação em Psicologia da UFES. Endereço: Ariadne Dettmann Alves Universidade Federal do Espírito Santo. Programa de Pós-Graduação em Psicologia. Avenida Fernando Ferrari, 514. Vitória-ES, Brasil. CEP: 29075910. E-mail: alves.ariadne@gmail.com.

"Professora doutora do Departamento de Psicologia Social e do Desenvolvimento e do Programa de Pós-Graduação em Psicologia da UFES.

*** Professor doutor colaborador e pesquisador do Programa de Pós-Graduação em Psicologia da UFES.
} 
loving a friend, an enemy and a stranger, using the clinical method. Most participants said it was possible to love a friend, highlighting the friendship aspect. However few agreed with the possibility of loving an enemy and argued primarily due to negative action of that person. Fewer still thought it possible to love a stranger, justifying the absence of a bond. Although few have stated the possibility of loving an enemy, we found that this number increased with age, which may indicate a genesis of this idea of love. This work could contribute to expansion of studies in the field of morality, providing theoretical support to aid practices in moral education.

Keywords: Moral development. Virtues. Love. Bonds. Children.

\section{Resumen}

El objetivo de este trabajo es explorar la influencia del vínculo (amigo y enemigo) o su ausencia (desconocido) en la concepción de amor de niños. Entrevistamos, individualmente, a 40 escolares (6 y 9 años) sobre la posibilidad de que un niño ame a un amigo, a un enemigo y a un desconocido, utilizando el método clínico. La mayoría de los participantes afirmó que se podía amar a un amigo, destacando la amistad. No obstante, pocos estuvieron de acuerdo con la posibilidad de que fuera a un enemigo, argumentando principalmente que era debido a la acción negativa de esa persona. Un número aún menor consideró que era posible amar a un desconocido, justificándolo en la falta del vínculo. A pesar de que pocos han afirmado la posibilidad de amar a un enemigo, constatamos que el número aumentó con la edad, lo que puede indicar una génesis de esa concepción de amor. Este trabajo puede contribuir a ampliar los estudios en el área de la moralidad, proporcionando elementos teóricos a prácticas de educación en valores morales.

Palabras clave: Desarrollo moral. Virtudes. Amor. Vínculos. Niños.

\section{Introdução}

W este artigo, temos por objetivo analisar os juízos de crianças sobre a existência do amor nos vínculos de relacionamentos ou na sua ausência. Nossa indagação foi: as crianças acreditam na existência do amor nas relações com amigo, inimigo e desconhecido? Para responder a essa questão, primeiramente, discutiremos alguns conceitos sobre o amor, sua possível existência nesses vínculos e qual a relação desse tema com a Psicologia da moralidade.

Para definir o amor, Comte-Sponville (1999) propõe três respostas: eros, philia e ágape. Eros é a paixão amorosa, caracteriza-se pelo desejo de se unir a outra metade. Esse amor se relaciona à possessividade, sendo rico em sofrimento, 
fracasso, ilusões e desilusões. É amar o outro para nosso próprio bem. Philia é o amor da amizade, é o querer bem dos amigos por amor a eles, e não por um interesse próprio. Entretanto, segundo esse autor, esse amor não é totalmente desinteressado, uma vez que o interesse de nossos amigos também é nosso interesse. Aristóteles (1992) afirma que a vida sem a amizade seria um erro, pois ela é condição para a felicidade. Por sua vez, ágape é o amor divino, sendo desinteressado e universal, ou seja, é amar a todos, inclusive os inimigos e desconhecidos. É renunciar seu prazer em função do amor ao outro (ComteSponville, 1999). Betto e Cortella (2007) também discorrem que o amor deve ser direcionado aos inimigos, sendo a máxima do amor: querer o bem de todos, mesmo que alguém lhe faça mal. Entretanto, de acordo com esses autores, temos dificuldade em praticar esse amor devido ao nosso egoísmo e ao incentivo da cultura em pensarmos em nós mesmos. Nesse sentido, La Taille (2009) afirma que a prioridade das pessoas hoje é a busca de divertimento e constantes prazeres. Nesse contexto, o outro é invisível, uma vez que "cada um fica centrado em seu pequeno 'universo particular', despreocupado ou inconsciente da presença de outrem e de seus anseios" (p. 201). Assim, cada um busca seus próprios interesses sem se preocupar com quem está ao seu redor.

Bauman (2004) considera egoísta a ideia do amor. Para ele, quando investimos em uma relação, esperamos um retorno: a sensação de segurança, o apoio, a companhia, o consolo. Com a chegada da era digital, os "relacionamentos" estariam sendo substituídos por relações mais frágeis, havendo facilidade em seu rompimento, podendo ser estabelecidas e cortadas por escolha. Esse autor afirma, portanto, a existência da fragilidade dos vínculos humanos.

Por outro lado, Godbout (1999) descreve a existência de amor nos vínculos de relacionamento, discorrendo sobre a dádiva: fazer o bem, sem garantia de retorno, visando à criação ou alimentação de vínculos entre as pessoas. Entretanto a retribuição existe mesmo que não seja desejada. Ressalta sua ocorrência na família (onde ela pode ser vivida com mais intensidade, devido ao vínculo incondicional), na amizade (na qual as estruturas são mais livres) e entre desconhecidos, demonstrando altruísmo, indo além das esferas pessoais. Principalmente as religiōes encorajam esse tipo de dádiva, que seria "amar ao próximo”, mas esse autor ressalta que o próximo deve se referir à humanidade inteira.

Em contraste com essa menção ao amor a desconhecidos, Cortella e La Taille (2009) salientam que hoje temos medo do que (ou de quem) não conhecemos. Para exemplificar essa ideia, Cortella e La Taille (2009) discutem que, se caminhássemos por uma rua escura e deserta na década de 1970, o medo existente era de assombração. Hoje, se estivermos na mesma rua, em situação idêntica, o 
medo não é mais de fantasmas, mas sim do outro que possa se aproximar de nós. Dessa forma, temos medo prévio de quem não conhecemos.

Apesar das discussões existentes sobre o amor, esse tema é pouco estudado na Psicologia da moralidade. Em nossa revisão de literatura, encontramos pesquisas principalmente sobre justiça (Menin, 2000; Müller, 2008; Sales, 2000; Sampaio, Camino \& Roazzi, 2007), generosidade (La Taille, 2006a; Tognetta, 2006; Vale, 2006; Vale \& Alencar, 2008a, 2008b, 2009), solidariedade (D'Aurea-Tardelli, 2008; Tognetta \& Assis, 2006), gratidão (Pieta \& Freitas, 2009; Freitas, Silveira \& Pieta, 2009a, 2009b), amor (Alves, Alencar \& Ortega, 2010; Costa, 2007, 2008), entre outros.

Devemos mencionar mais detalhadamente a pesquisa de Vale e Alencar (2009), devido a sua relação com nosso estudo. As autoras analisaram a influência do vínculo existente (ou não) para a prática do ato generoso, em crianças e adolescentes de 7, 10 e 13 anos. Verificaram que, nas situaçóes de amizade, todos os participantes decidiram pela generosidade. $\mathrm{Na}$ ausência de vínculo (desconhecido), a maior parte dos entrevistados optou pela virtude, entretanto a generosidade para com um desconhecido seria menos intensa do que para com um amigo. Por sua vez, na situação de inimizade, a maioria decidiu pela ausência do ato virtuoso. Suas justificativas remetiam a, principalmente, tipo de vínculo ou sua ausência nas três situações. Portanto existe relação entre o vínculo e a generosidade para esses participantes.

Gostaríamos de nos referir ao trabalho de Souza e Ramires (2006), que investigaram a concepção de amor em crianças e adolescentes de 5 a 15 anos de idade, em estudo sobre casamento, relacionamentos familiares e divórcio. Constataram que o amor constitui-se como elo nos relacionamentos entre pais e filhos, na amizade e nos relacionamentos amorosos. Os participantes consideraram a família como vínculo mais importante, seguido da amizade.

Dessa forma, apesar de pouco estudado nessa área, podemos refletir a relação do amor com a moral. Para Comte-Sponville (1999), somente necessitamos de moral porque nos falta amor. Dessa forma, se tivéssemos amor, não precisaríamos de moral. Mas o autor afirma, ainda, que só seria possível nos desenvolvermos moralmente por causa do amor que temos.

Diante dessas considerações a respeito da relação do amor e da moral, devemos explicitar alguns aspectos do desenvolvimento. De acordo com Piaget (1994) o juízo moral constitui-se em duas fases: heteronomia e a autonomia. $\mathrm{Na}$ heteronomia, a criança considera correto todo ato que seja uma obediência a regras impostas pela figura de autoridade. Considera as regras imutáveis e tende a interpretá-las ao pé da letra. Há o predomínio do respeito unilateral. A criança 
respeita os pais (ou outra figura de autoridade) por medo e amor - medo das punições e de perder o amor e proteção dos pais, e devido ao apego e admiração que tem por eles.

Por outro lado, na autonomia, a criança passa a agir por reciprocidade, predominando o respeito mútuo. As regras começam a ser compreendidas e interpretadas, permitindo a ela própria fazer suas avaliações morais. Piaget (1994) ressalta que nenhuma criança é totalmente heterônoma ou autônoma: as concepções a respeito da moral começam a mudar, no entanto isso não significa que essa nova forma de pensar a moral substitua inteiramente a anterior.

É importante destacarmos que, para o desenvolvimento do pensamento autônomo, é necessária a diminuição do egocentrismo característico do período pré-operatório (aproximadamente de 2 a 7 anos), que se caracteriza pela dificuldade da criança em diferenciar seus pensamentos e os pensamentos dos outros, e assim a impossibilitando de se colocar na perspectiva do outro.

Retornando à discussão a respeito do desenvolvimento moral, La Taille (2006b) afirma que há algo que é comum a todas as expressões de moralidade: o sentimento de obrigatoriedade, que é o sentimento do dever. Esse autor discorre ainda sobre a dimensão intelectual da ação moral, "saber fazer", e a dimensão afetiva da ação moral, "querer fazer", sendo ambas necessárias para a ação moral.

Sobre a dimensão intelectual, La Taille (2006b) assinala que, para o desenvolvimento da ação moral, é necessário o conhecimento das regras e princípios, e também a consciência de quais são os nossos valores, sendo eles "o resultado de um investimento afetivo" (p. 74), ou seja, remete-nos à energética da vida moral. Por sua vez, o "querer fazer moral" se refere à vontade de agir e à intenção com a qual se age. Esse autor evidencia seis sentimentos que inspiram um "querer agir moral": medo, amor, confiança, simpatia, indignação e culpa. Concorda, portanto, com Piaget, afirmando que o medo e o amor são indissociáveis para o sentimento de obrigatoriedade presente na ação moral, explicando o "querer fazer" heterônomo.

Dessa forma, com base na relação do amor com a moral e na importância dessa virtude, nosso objetivo é investigar e comparar, em uma perspectiva psicogenética, os juízos de crianças, no que diz respeito à existência ou não do amor nos vínculos de relacionamento (amigo e inimigo) e na ausência de vínculo (desconhecido). 


\section{Metodologia \\ Participantes}

Neste estudo, participaram 40 crianças de classe média de uma escola particular do município de Vila Velha- ES, sendo metade com 6 anos e metade com 9 anos, e, ainda, igualmente divididos quanto ao sexo. Selecionamos os participantes por sorteio, levando em consideração essas variáveis.

\section{Instrumento e procedimento}

Realizamos entrevistas individuais, de acordo com o método clínico proposto por Piaget (2005, 1994). Perguntamos aos participantes: um menino da sua idade pode amar um amigo? Por quê? Um menino da sua idade pode amar um desconhecido? Por quê? Um menino da sua idade pode amar um inimigo? Por quê? Ressaltamos que as perguntas foram formuladas de acordo com o sexo do entrevistado.

Para a coleta de dados, obtivemos a permissão da direção da escola e dos pais dos alunos sorteados, por meio de assinatura dos termos de consentimentos. Os participantes de 9 anos assinaram um termo de assentimento. Além disso, as crianças de 6 anos foram esclarecidas verbalmente sobre os objetivos, procedimentos da pesquisa e sigilo das informações. Destacamos também que essa pesquisa segue os padrões éticos da Resolução no 196/1996 do Ministério da Saúde.

\section{Tratamento dos dados}

As entrevistas foram gravadas na íntegra para fins exclusivamente de pesquisa. Discutimos os dados com base na teoria piagetiana e na sistematização proposta por Delval (2002). Dessa forma, elaboramos, com base nas transcrições, categorias detalhadas para as respostas e justificativas dos participantes, para, em seguida, agrupá-las em categorias resumidas, para uma análise por questão do instrumento e de acordo com as idades dos participantes. Nossa prioridade foi, portanto, a análise qualitativa dos dados. Para o auxílio na apresentação e discussão dos resultados, utilizamos referências quantitativas em números e percentuais.

No decorrer do artigo, para nos referir ao participante, respeitando o anonimato, utilizamos nomes fictícios, seguidos da idade, entre parênteses. Escolhemos nomes iniciados com a letra "A" para as crianças de 6 anos, e com a 
letra "F" para as de 9 anos.

\section{Resultados e discussão}

Para apresentação e discussão dos dados, analisaremos as questōes referentes ao amigo, ao inimigo, e, por último, ao desconhecido.

\section{Possibilidade de amar um amigo}

Constatamos que $87,5 \%$ dos escolares afirmaram que uma criança de mesma idade poderia amar um amigo, sendo 17 crianças de 6 anos e 18 de 9 anos. Nossos dados estão de acordo com Souza e Ramires (2006), uma vez que essas autoras mencionam que crianças e adolescentes consideram esse vínculo muito importante. Além disso, Vale e Alencar (2009), pesquisando sobre a influência do vínculo para a ação generosa, relatam que todos os seus participantes $(7,10 \mathrm{e}$ 13 anos) optaram pela generosidade em relação ao amigo.

Da mesma forma, em nossa introdução, descrevemos algumas pesquisas nas quais se ressalta a importância da amizade. Assim, Comte-Sponville (1999) discute que o amor philia é a amizade, sendo esta a vontade de fazer o bem aos amigos, por amor a eles. Assim, a vida sem a amizade seria um erro, pois, baseando-se em Aristóteles, essa é a condição para a felicidade. Por sua vez, Godbout (1999) reflete que, na amizade, é possível o desenvolvimento da dádiva, ainda mais que nessa relação escolhemos nossos amigos.

Analisemos agora as justificativas (Tabela 1), ressaltando que cada participante pôde mencionar mais de um argumento.

\section{Tabela 1 - Justificativas dos participantes para a possibilidade (ou não) de amar um(a) amigo(a) de acordo com a idade}

\begin{tabular}{l|c|c|c|c|c|c}
\hline \multirow{2}{*}{ Categoria } & \multicolumn{2}{|c|}{6 anos } & \multicolumn{2}{c|}{9 anos } & \multicolumn{2}{c}{ Geral } \\
\cline { 2 - 7 } & $\mathrm{n}^{\circ}$ & $\%$ & $\mathrm{n}^{\circ}$ & $\%$ & $\mathrm{n}^{\circ}$ & $\%$ \\
\hline Relacionamento de amizade & 5 & 16,1 & 6 & 17,1 & 11 & 16,7 \\
$\begin{array}{l}\text { Observação de experiência } \\
\text { vivenciada }\end{array}$ & 4 & 12,9 & 7 & 20,0 & 11 & 16,7 \\
$\begin{array}{l}\text { Consequência positiva para si } \\
\text { próprio } \\
\text { Consequência positiva }\end{array}$ & 2 & 6,5 & 8 & 22,9 & 10 & 15,2 \\
$\begin{array}{l}\text { recíproca } \\
\text { Sentimento }\end{array}$ & 3 & 9,6 & 6 & 17,1 & 9 & 13,6 \\
$\begin{array}{l}\text { Característica positiva da } \\
\text { pessoa amada }\end{array}$ & 3 & 9,6 & 6 & 17,1 & 9 & 13,6 \\
\end{tabular}




\begin{tabular}{l|c|c|c|c|c|c}
$\begin{array}{l}\text { Consequência positiva } \\
\text { indefinida }\end{array}$ & 2 & 6,5 & 0 & 0,0 & 2 & 3,0 \\
Argumento circular & 2 & 6,5 & 0 & 0,0 & 2 & 3,0 \\
Não soube responder & 2 & 6,5 & 0 & 0,0 & 2 & 3,0 \\
Outros & 4 & 12,9 & 2 & 5,8 & 6 & 9,1 \\
Total & 31 & 100,0 & 35 & 100,0 & 66 & 100,0 \\
\hline
\end{tabular}

Fonte: elaborado pelos autores.

Podemos verificar que os escolares justificaram, principalmente, com base no "relacionamento de amizade" e na "observação de experiência vivenciada". As explicaçôes sobre "relacionamento de amizade" se referem à própria condição do vínculo, como menciona Frederico: uma criança pode amar um amigo "porque eles podem ser melhores amigos", reforçando a importância desse tipo de vínculo.

Vale e Alencar (2009) também descreveram essa justificativa em sua pesquisa. Mais da metade de seus participantes ressaltam a amizade como motivo para a manifestação da generosidade. Com base nessas considerações, podemos questionar: seria possível ter amor àqueles que não são nossos amigos, como aos desconhecidos, ou, ainda, aos inimigos? É o que discutiremos após analisarmos os outros motivos para a possibilidade (ou não) de amar um amigo.

Por sua vez, "observação de experiência vivenciada" diz respeito às experiências próprias ou vividas por outras pessoas. Vejamos um trecho da entrevista de Fabiana: "Porque eu também amo muitas amigas minhas". Constatamos, portanto, a influência das experiências na formulação de seus juízos. Além disso, sendo esse argumento mencionado, principalmente, pelos escolares de 9 anos, podemos refletir que, com o desenvolvimento, as crianças passam a usar mais as experiências para justificar o juízo.

Em seguida, temos a "consequência positiva para si próprio", ou seja, é possível amar um amigo "porque ele te ajuda muito" (Fábio), por exemplo. Assim, a possibilidade de amar uma pessoa com esse vínculo está relacionada ao ganho que a pessoa terá desse amor. Essa ideia da espera de um retorno quando se investe em uma relação é considerada por Bauman (2004). Segundo esse autor, quando nos relacionamos, esperamos um ganho que pode ser um apoio quando há necessidade, a companhia da pessoa, entre outros. Essa concepção é contrária ao conceito de Comte-Sponville (1999) sobre philia, a vontade de fazer o bem, por amor a ele. Também não corresponde à amizade perfeita de Aristóteles (1992), ou seja, a vontade de fazer o bem ao amigo, pela amizade, e não por interesse pessoal. 
Constatamos, portanto, o interesse de benefício próprio e que a quantidade desse argumento aumentou com a idade. Assim nos indagamos: com o decorrer do desenvolvimento e a diminuição do egocentrismo, explicações como essas não deveriam ser cada vez menos frequentes? Nossos dados mostram o contrário, os escolares de 9 anos citaram mais esse motivo do que os de 6 anos. Podemos refletir se não haveria a influência da cultura no acréscimo dessas explicações, uma vez que, segundo Betto e Cortella (2007), além de La Taille (2009), ela nos incentiva a buscarmos o que é de nosso interesse pessoal, ou seja, uma postura egoísta.

Diferente desse tipo de explicação, em "consequência positiva recíproca" ambos são beneficiadores da relação de amor. Dessa forma, fundamenta Flávio: "Porque eles fazem muita coisa juntos". Assim a possibilidade de amar é devido a um benefício mútuo. Essa concepção se aproxima da ideia de Godbout (1999) sobre philia, uma vez que, para esse autor, está relacionada à reciprocidade. Ressaltamos que as justificativas sobre o benefício mútuo da relação de amor também aumentaram com a idade, evidenciando a importância da reciprocidade, que nos permite relacionar com a possível diminuição do egocentrismo, comum no período pré-operatório, e o aumento das relaçôes de cooperação e, por conseguinte, permitindo o desenvolvimento da autonomia.

Com a mesma frequência que "consequência positiva recíproca", foi mencionado o "sentimento". Assim, a possibilidade de amor se fundamenta pelo que uma pessoa sentiria pela outra. Ressaltamos o depoimento de Ângela: "Porque ela gosta muito dessa pessoa". De acordo com Souza e Ramires (2006), as crianças usam esse argumento para definir o amor, tornando-se mais frequente e detalhado com a idade. Assim, está de acordo com nossos dados, uma vez que constatamos um aumento nesse tipo de explicação no grupo de escolares mais velhos. Além disso, com o desenvolvimento, a criança se torna capaz de refletir cada vez mais sobre temas abstratos.

Apenas os escolares de 6 anos explanaram sobre a "característica positiva da pessoa amada", "consequência positiva indefinida", "argumento circular" e "não soube responder". Vejamos cada uma delas. A justificativa sobre "característica positiva da pessoa amada” estabelece que a possibilidade de amor seja devido às características do amigo, sendo estas positivas. Por exemplo, para Adilson, uma criança pode amar um amigo "porque acha o amigo legal, divertido", ou seja, pelos seus atributos. Podemos refletir se o fato de salientarem as qualidades de outrem, não haveria como pano de fundo um interesse próprio que esses atributos poderiam resultar. Assim haveria proximidade entre a "característica positiva da pessoa amada" com a "consequência positiva para si próprio". Podemos nos questionar se dessa referência às características positivas do outro seria possível 
o amor ao desconhecido (que não sabemos seus atributos) e ao inimigo (que possivelmente tem aspectos negativos). $\mathrm{Na}$ concepção das crianças, haveria o amor ágape? Analisaremos essas indagações no decorrer do texto.

As crianças argumentaram, ainda, sobre "consequência positiva indefinida", na qual não é definido o beneficiário da relação de amor. $\mathrm{O}$ depoimento de Almir exemplifica esse argumento: "Porque quando vai de férias, o amigo [...] fica no mesmo hotel". Constatamos que se trata de uma consequência positiva ficar no mesmo hotel, mas não podemos afirmar quem se favoreceria.

Foi mencionado também, apenas pelos escolares de 6 anos, "argumento circular", evidenciando a dificuldade de algumas crianças fundamentarem suas respostas. De acordo com Piaget (1994), essa dificuldade em expor os motivos de seus juízos ocorre devido ao pensamento egocêntrico, pois a criança acata cegamente a regra, já que, para ela, o que vem do outro lhe é superior, não desenvolvendo seus próprios conceitos. Além disso, os participantes mais novos foram os únicos que afirmaram não saber responder à pergunta (que constituiu a categoria "não soube responder").

Por fim, agrupamos em "outros" os argumentos que não poderiam ser incluídos nas categorias anteriores e foram mencionados apenas uma vez. Foram explicaçôes sobre a "consequência positiva para outrem"; "motivos religiosos"; "a proibição"; "a condição de ainda ser criança"; "o fato de a pessoa ser o próximo", e "a atitude de achar estranho".

\section{Possibilidade de amar um inimigo}

Quando investigamos a possibilidade de amar um inimigo, apenas 37,5\% do total de participantes afirmaram ser possível amar um inimigo, e mais da metade (55\%) negou essa possibilidade. Além disso, 7,5\% responderam que "depende", como afirma Felipe: "Se eles forem amigos, terem brigado e tornado inimigos". Comparamos nossos dados com os de Vale e Alencar (2009) uma vez que a maioria de seus entrevistados optou pela ausência de generosidade para com o inimigo. Em ambos os estudos, os participantes optaram pela ausência da virtude para com o inimigo. Constatamos diferenças nas respostas dos escolares de acordo com a idade, como está apresentado na Figura 1. 


\section{Figura 1 - Possibilidade de amar um inimigo: comparação das respostas conforme a idade}

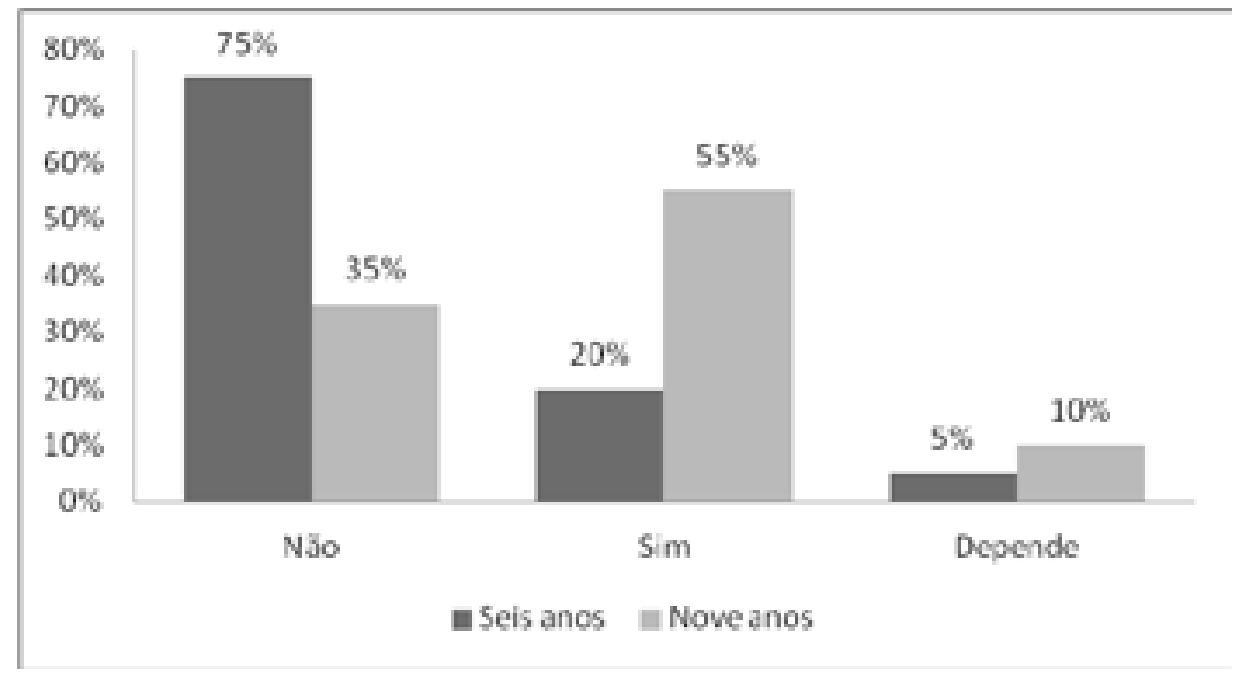

Fonte: elaborado pelos autores.

Vejamos que a maioria das crianças de 6 anos afirmou não ser possível amar um inimigo. Entretanto mais da metade dos escolares de 9 anos disseram que esse amor era possível. Analisando novamente os dados de Vale e Alencar (2009), verificamos que houve predominância das respostas sobre ausência de generosidade nas idades de 7 e 13 anos, sendo que, dos participantes que afirmaram a ação virtuosa, a maioria tinha 10 anos. Verificamos que, nos dois estudos, os mais novos optaram pela ausência da virtude, posteriormente, no segundo grupo, a escolha pela virtude se tornou mais frequente. Além disso, nesse estudo de Vale e Alencar (2009), a ação virtuosa tornou a decrescer com a idade.

Apesar de poucos declararem a possibilidade do amor ao inimigo, constatamos o aumento com a idade. Será que nossos dados demonstram a gênese do amor ágape? Comte-Sponville (1999) e Betto e Cortella (2007) discorrem que ágape é amar o desconhecido e até mesmo nossos inimigos, sendo a máxima do amor: amar até quem me quer o mal. No entanto, apesar do aumento das afirmativas sobre a possibilidade de amar um inimigo, devemos analisar as justificativas mencionadas pelas crianças, para compreender seus raciocínios. Além disso, como estamos investigando em apenas duas faixas etárias, não podemos confirmar que, nos mais velhos, essa construção se mantém. Os argumentos dados por nossos participantes foram variados, como apresentamos na tabela 2. 
Tabela 2 - Justificativas dos participantes para a possibilidade (ou não) de amar um(a) inimigo(a) de acordo com a idade

\begin{tabular}{|c|c|c|c|c|c|c|}
\hline \multirow{2}{*}{ Categoria } & \multicolumn{2}{|c|}{6 anos } & \multicolumn{2}{|c|}{9 anos } & \multicolumn{2}{|c|}{ Geral } \\
\hline & $\mathrm{n}^{\circ}$ & $\%$ & $\mathrm{n}^{\circ}$ & $\%$ & $\mathrm{n}^{\circ}$ & $\%$ \\
\hline Ação negativa do(a) inimigo(a) & 10 & 31,3 & 3 & 10,0 & 13 & 20,9 \\
\hline Observação de experiência vivenciada & 1 & 3,1 & 5 & 16,6 & 6 & 9,7 \\
\hline Dúvida em relação ao sentimento & 4 & 12,5 & 2 & 6,7 & 6 & 9,7 \\
\hline $\begin{array}{l}\text { Sentimento de não gostar do(a) } \\
\text { inimigo(a) }\end{array}$ & 1 & 3,1 & 4 & 13,3 & 5 & 8,1 \\
\hline $\begin{array}{l}\text { Possibilidade de amar independente de } \\
\text { ser inimigo(a) }\end{array}$ & 1 & 3,1 & 4 & 13,3 & 5 & 8,1 \\
\hline Possibilidade de amizade & 1 & 3,1 & 4 & 13,3 & 5 & 8,1 \\
\hline Característica negativa do(a) inimigo(a) & 5 & 15,7 & 0 & 0,0 & 5 & 8,1 \\
\hline Ação negativa recíproca & 2 & 6,3 & 1 & 3,4 & 3 & 4,8 \\
\hline $\begin{array}{l}\text { Característica ou ação positiva do(a) } \\
\text { inimigo(a) }\end{array}$ & 1 & 3,1 & 2 & 6,7 & 3 & 4,8 \\
\hline $\begin{array}{l}\text { Possibilidade de mudança da } \\
\text { característica do(a) inimigo(a) }\end{array}$ & 1 & 3,1 & 1 & 3,4 & 2 & 3,2 \\
\hline Outros & 4 & 12,5 & 4 & 13,3 & 8 & 12,9 \\
\hline Dado perdido & 1 & 3,1 & 0 & 0,0 & 1 & 1,6 \\
\hline Total & 32 & 100,0 & 30 & 100,0 & 62 & 100,0 \\
\hline
\end{tabular}

Fonte: elaborado pelos autores.

Constatamos que a principal justificativa foi devido à "ação negativa do (a) inimigo(a)". Assim, não seria possível amar um inimigo porque "o inimigo pode matar. [...] Porque ele pode pegar a arma e atirar no coração, ou na barriga" (Alexandre). Destacamos que essa explicação foi a mais citada pelos escolares de 6 anos. As demais categorias tiveram uma frequência geral inferior a $10 \%$.

Os escolares argumentaram também pela "observação de experiência vivenciada". Como na questão anterior (sobre amar um amigo), sua referência aumentou com a idade. A afirmação de Andreia exemplifica esse fundamento: "Porque meu pai tinha uma inimiga, e ele gostava dela. [...] Meu pai não, o amigo do meu pai". 
Com a mesma frequência geral de "observação de experiência vivenciada" foi mencionado "dúvida em relação ao sentimento", remetendo para uma dúvida entre amar e odiar. Dessa forma, a pessoa acharia que não ama, mas, na verdade, ama outrem. Ressaltamos que essa categoria diminuiu com a idade. Para melhor compreensão, eis o depoimento de Franciele:

Pode ser que ela pense que a odeia, escondendo dela mesma que ela gosta dessa menina. [...] Tipo, eu vou dar um exemplo: você é minha inimiga, eu te odeio, eu acho você muito chata, e você me acha muita chata. Ai eu posso estar escondendo de mim mesma que, no fundo, eu gosto de você.

Alguns escolares justificaram simplesmente pelo "sentimento de não gostar do inimigo(a)", desta forma, não é possível amá-lo "porque ele não gosta dessa pessoa, se é inimigo. [...] Porque ele não gosta dela. Como vai amar?" (Flávio). Portanto está presente a ideia da impossibilidade de amor ágape.

Se somarmos as duas categorias que referem a sentimentos ("dúvida em relação ao sentimento" e "sentimento de não gostar do inimigo(a)"), chegamos ao total de $17,8 \%$, ou seja, seria o segundo argumento mais mencionado. Analisando, constatamos que as crianças mais novas afirmam principalmente sobre a "dúvida em relação ao sentimento", e os mais velhos relatam o "sentimento de não gostar do inimigo(a)". Assim, primeiro o foco estaria no próprio sentimento e, posteriormente, na condição de inimigo.

Diferentemente dessa explicação, outros participantes afirmam a "possibilidade de amar independente de ser inimigo". Dessa maneira, afirma Fausto: "Você pode amá-lo, mas ele pode náo te amar"; logo, a pessoa pode amar mesmo que o inimigo a odeie. Nessa concepção, o amor não necessita de reciprocidade, aproximando-se da concepção de amor ágape descrito por Comte-Sponville (1999) como amor desinteressado e gratuito. Afirmam Betto e Cortella (2007) que essa seria a máxima do amor, querer bem de todos, mesmo que eles nos façam mal. Constatamos um acréscimo com a idade. Dessa forma, sugerimos novamente que estudos possam ser realizados para confirmar se esse aumento permanece no decorrer do desenvolvimento.

Outra justificativa que também foi mais citada pelos escolares maiores evidencia a "possibilidade de amizade", exemplificado no seguinte depoimento: "A gente pode conversar, se adireitar, depois a gente vira melhores amigas de novo" (Andressa). Assim, é possível amar pela possibilidade de tornarem a ser amigas. Como vimos na questão sobre a possibilidade de amar um amigo, os participantes fundamentaram principalmente pelo próprio vínculo existente. Assim, quanto ao inimigo, permanece o mesmo raciocínio, mas não existindo a relação entre amigos, as crianças argumentaram pela possibilidade da amizade, ressaltando novamente a importância desse vínculo. 
Apenas os mais novos argumentaram pela "característica negativa do(a) inimigo(a)". Adilson afirma, por exemplo, que "ele [o inimigo] é muito mal". Esse dado está consoante com a questão anterior, uma vez que somente as crianças de 6 anos justificaram pela característica positiva da pessoa amada. Dessa forma, o foco nas características do outro permanece.

Outra explicação citada foi a "ação negativa recíproca". Diferencia-se da "ação negativa do(a) inimigo(a)", porque aqui são os dois que cometem a ação negativa, e não só o inimigo, como na anterior. Vejamos a explanação de Alan, afirmando não ser possível amar um inimigo: "[Porque] eles brigam. [...] Ficam batendo um no outro". Contrariamente a essa justificativa, temos a "característica ou ação positiva do(a) inimigo(a)". Assim, pode-se amar um inimigo "porque, às vezes, quando você está em um momento difícil, ele pode te ajudar. Sem querer ou querendo, ele pode te ajudar a fazer o que você quer” (Fernando).

Há aqueles que acreditam na "possibilidade de mudança da característica do inimigo (a)" e esta seria a condição para amar. Assim, para Antônio, é possível amar um inimigo "porque o inimigo, numa hora, ele fica bonzinho". Aqui o amor não se daria pelo vínculo, mas sim pela esperança da mudança.

Em "outros", reunimos as justificativas sobre a possibilidade de amar devido "a motivos religiosos"; o "dever de amar a todos"; a "escolha que a pessoa tem de amar ou não a inimiga"; e ainda, a impossibilidade de amar devido a: "afirmação da condição de inimiga"; pela ação "negativa da própria criança"; o "fato de o inimigo não gostar da pessoa"; o "fato de não conhecer a pessoa"; e mais a afirmação de que "não sabia responder". Além disso, um participante não conseguiu responder à questão, configurando em "dado perdido".

\section{Possibilidade de amar um desconhecido}

Por último, indagamos sobre a ausência de vínculo. Apenas $27,5 \%$ das crianças afirmaram que poderia amar um desconhecido (sendo 6 escolares de 6 anos e 5 de 9 anos). Podemos relacionar nossos dados com a análise sobre generosidade realizada por Vale e Alencar (2009). A maior parte de seus entrevistados optou pela virtude para com o desconhecido, entretanto foi menos intensa se comparado à generosidade em relação ao amigo. Constatamos, portanto, que a ausência do vínculo influenciou no juízo das crianças. Vejamos, na tabela 3, as justificativas mencionadas. 
Tabela 3 - Justificativas dos participantes para a possibilidade (ou não) de amar um(a) desconhecido(a) de acordo com a idade

\begin{tabular}{l|c|c|c|c|c|c}
\hline \multirow{2}{*}{ Categoria } & \multicolumn{2}{|c|}{6 anos } & \multicolumn{2}{c|}{9 anos } & \multicolumn{2}{c}{ Geral } \\
\cline { 2 - 7 } & $\mathrm{n}^{\circ}$ & $\%$ & $\mathrm{n}^{\circ}$ & $\%$ & $\mathrm{n}^{\circ}$ & $\%$ \\
\hline Não conhecer a pessoa & 9 & 31,0 & 12 & 40,0 & 21 & 35,6 \\
Ação negativa do(a) desconhecido(a) & 5 & 17,2 & 6 & 20,0 & 11 & 18,6 \\
Característica negativa do(a) & 5 & 17,2 & 2 & 6,7 & 7 & 11,8 \\
desconhecido(a) & & & & & & \\
Observação de experiência vivenciada & 3 & 10,3 & 2 & 6,7 & 5 & 8,5 \\
Possibilidade de amizade & 3 & 10,3 & 2 & 6,7 & 5 & 8,5 \\
Possibilidade de amar uma pessoa do & 1 & 3,5 & 2 & 6,7 & 3 & 5,1 \\
mesmo sexo & 1 & 3,5 & 2 & 6,7 & 3 & 5,1 \\
Não dever & 2 & 7,0 & 2 & 6,7 & 4 & 6,8 \\
Outros & 29 & 100,0 & 30 & 100,0 & 59 & 100,0 \\
Total & & & & & & \\
\hline
\end{tabular}

Fonte: elaborado pelos autores.

A justificativa com maior frequência foi o próprio fato de "não conhecer a pessoa", sendo mais mencionado pelas crianças de 9 anos. A explanação de Fabiana exemplifica esse argumento: "Porque a gente não conhece a pessoa. Não a conhece direito", ou seja, não é possível amar o desconhecido pela própria ausência do vínculo. Vale e Alencar (2009) também discutem categoria semelhante à nossa. A metade de seus participantes utilizou a ausência de vínculo para explicar a ausência de generosidade ou a intensidade da ação generosa para com o desconhecido. Ressaltamos novamente a importância do vínculo para a relação de amor.

Nossos entrevistados afirmaram também sobre a possibilidade de uma "ação negativa do(a) desconhecido(a)", não sendo possível amar o desconhecido "porque o desconhecido pode assaltar sua casa, ou te matar" (Fabrício). Ou ainda "Quando faz assim 'quer uma bala?', pode estar envenenada" (Almir). Essas explicaçõos lembram a preocupação dos pais para com pessoas desconhecidas, recomendando que seus filhos não falem ou aceitem algo de estranhos. Semelhante a esse argumento, temos a "característica negativa do(a) desconhecido(a)". Aqui ressaltam uma possível característica negativa, que remete ao perigo que o desconhecido pode causar, como afirma Augusto: "Porque pode ser um ladrão. Uma pessoa fantasiada que a gente pode até perceber uma arma e não pode chegar perto dele". Esse motivo foi evidenciado, principalmente, pelas crianças mais novas.

Se somarmos "ação negativa do(a) desconhecido(a)" e "característica negativa do(a) desconhecido(a)", constatamos um total de $30,4 \%$, salientando um medo existente 
pelo desconhecido. Esse dado está de acordo com a discussão de Cortella e La Taille (2009) sobre o medo que temos de quem não conhecemos. Para eles, construímos um medo prévio do que é por nós desconhecido.

Se analisarmos por idade, constatamos que as menções sobre "característica negativa do(a) desconhecido(a)" diminuem na medida em que "não conhecer a pessoa" aumentam. As crianças passam a argumentar pela própria ausência do vínculo, reduzindo os juízos da possível ação do outro. Assim, nós nos questionamos se essa alteração continuaria no decorrer do desenvolvimento. Mas, para essa verificação, é necessário que novos estudos sejam realizados.

As outras justificativas foram mencionadas com menor frequência. Alguns explicaram pela "observação de experiência vivenciada", tanto para a possibilidade de amar quanto para a impossibilidade. Ressaltamos que essa categoria também foi citada nas questôes sobre amigo e inimigo.

As crianças afirmaram ainda que poderiam amar um desconhecido devido à "possibilidade de amizade": "Porque aí elas vão fazer amizade" (Alana), ressaltando o vínculo da amizade como consequência da relação de amor. Salientamos que essa justificativa também foi referida quanto à possibilidade de amar um inimigo. Vale e Alencar (2009) também constataram explicações sobre a amizade ser consequência da manifestação da generosidade.

Podemos verificar explicações sobre a "possibilidade de amar uma pessoa do mesmo sexo". Dessa forma, seria possível uma criança amar um desconhecido se ela gostar da pessoa do mesmo sexo. Vejamos a depoimento de Fabrícia: "Porque eu não tenho preconceito nenhum, se alguém gostar de uma menina, não tem problema, não sou contra isso". Apesar de termos perguntado sobre desconhecido, o foco do argumento não está na ausência do vínculo, e sim no fato de a outra pessoa ser do mesmo sexo. Por sua vez, "não dever" corresponde a justificativas sobre o que retiraria o dever de amar. Assim, não é possível amar um desconhecido "porque não pode falar com estranhos" (Adriana).

Em "outros" agrupamos os argumentos sobre a "ausência da necessidade de amar pela condição de ausência de vínculo", "característica positiva do desconhecido", "decisão da própria pessoa de amar ou não" e a "afirmação de não saber como essa relação de amor poderia acontecer".

\section{Relação entre possibilidade de amar amigo, inimigo e desconhecido}

A maioria dos participantes demonstrou ser o vínculo da amizade condição para a relação de amor. Resumindo, temos que $87,5 \%$ das crianças afirmaram ser possível o amor a um amigo, $37,5 \%$ a um inimigo e $27,5 \%$ ao desconhecido. 
Assim, para nossos entrevistados, mais difícil do que amar um inimigo é amar aquele que não se tem um vínculo. Essa análise difere um pouco da realizada por Vale e Alencar (2009), uma vez que, em seus dados, a ação generosa foi inferior na relação para com o inimigo.

Comparemos, agora, algumas justificativas nas três condições (amigo, inimigo e desconhecido). Constatamos que os argumentos mais usados foram baseados no próprio vínculo. Assim, para confirmar a possibilidade de amar um amigo, ressaltaram o relacionamento da amizade. Para a impossibilidade de amar um desconhecido, evidenciaram o fato de não conhecer a pessoa, ou seja, a ausência do vínculo. Afirmaram, ainda, que diante da possibilidade de amizade, aconteceria o amor ao desconhecido ou ao inimigo. Destacamos que foi mencionado o amor a um amigo devido à consequência positiva para si próprio. Quanto ao inimigo, utilizam-se, principalmente, da possibilidade de ação negativa por parte do inimigo para negar a possibilidade de amor. Esse argumento também foi citado em relação ao desconhecido.

Devemos ressaltar que foram referidas, nas três condições, explicações baseadas nas observações de experiência, demonstrando a influência das experiências na formulação de seus conceitos, e nas características da pessoa a ser amada: sendo ressaltados no amigo aspectos positivos; no desconhecido, negativos; e, no inimigo, tanto positivos quanto negativos.

\section{Considerações finais}

Com base nos resultados, verificamos que, para a maioria dos nossos participantes, o tipo de vínculo ou a sua ausência influencia no juízo sobre a possibilidade de amar outrem. Nesse sentido, grande parte das crianças afirmou ser possível amar um amigo, poucos concordaram com a possibilidade quanto ao inimigo, e um número ainda menor considerou ser possível amar o desconhecido.

Ressaltamos que, apesar de poucos terem afirmado a possibilidade de amar um inimigo, constatamos que o número aumentou com a idade, o que pode indicar uma gênese dessa concepção de amor. Alguns participantes disseram inclusive ser possível amar, independentemente da condição de inimigo, assim a possibilidade de amar não dependeria desse vínculo. Verificamos também o aumento dos argumentos sobre interesse próprio para as justificativas sobre a possibilidade de amar outra pessoa.

Não obstante devemos refletir sobre as limitaçôes de nosso estudo, principalmente em relação ao número de participantes. Como investigamos apenas duas faixas etárias, não podemos confirmar se essas tendências manter- 
se-iam com o desenvolvimento. Assim, sugerimos que novas pesquisas sejam feitas, investigando o juízo de pessoas de outras idades.

Tendo em vista a relação do amor com a moral, salientamos, portanto, a necessidade de discussões sobre essa virtude e ainda a sua possível manifestação para com amigos, inimigos e desconhecidos, contribuindo para o desenvolvimento moral de crianças. Com base nessas consideraçôes, este trabalho pode contribuir para a ampliação dos estudos na área da moralidade, fornecendo subsídios teóricos para a elaboração de projetos de educação em valores morais que considerem o processo de desenvolvimento infantil e contemplem a virtude do amor. Consideramos que a inserção dessa virtude nas propostas de educação em valores morais contemporâneas poderá enriquecer a formação moral de crianças.

\section{Referências}

Alves, A. D., Alencar, H. M. \& Ortega, A. C. (2010). Amor e moralidade: um estudo com participantes de 5 a 70 anos. Revista de Ciências Humanas, 44(2), 363-380.

Aristóteles (1992). Ética a Nicômaco. (2a ed.).(M. G. Kury, Trad.). Brasília: Universidade de Brasília. [Trabalho original publicado em 384-322 a.C.].

Bauman, Z. (2004). Amor líquido: sobre a fragilidade dos laços humanos. (C. A. Medeiros, Trad.). Rio de Janeiro: Jorge Zahar.

Betto, Frei \& Cortella, M. S. (2007). Sobre a esperança: diálogo. Campinas: Papirus.

Comte-Sponville, A. (1999). Pequeno tratado das grandes virtudes. São Paulo: Martins Fontes.

Cortella, M. S. \& La Taille, Y. (2009). Nos labirintos da moral. Campinas: Papirus.

Costa, F. A. B. S. (2007). A importância da virtude do amor e da vontade nas representações de si de professores. In L. R. P. Tognetta (Org.). Virtudes e educação: o desafio da modernidade (pp. 61-93). Campinas: Mercado de Letras.

Costa, F. A. B. S. (2008). Representaçôes de si de professores do ensino fundamental: um estudo sobre a virtude do amor. (Tese de Doutorado). Universidade de São Paulo, Instituto de Psicologia,São Paulo.

D'Aurea-Tardelli, D. (2008). A manifestação da solidariedade em adolescentes: um estudo sobre a personalidade moral. Psicologia Ciência e Profissão, 28(2), 288-303. 
Delval, J. (2002). Introdução à prática do método clínico: descobrindo o pensamento das crianças (F. Murad, Trad.). Porto Alegre: Artmed.

Freitas, L. B. de L., Silveira, P. G. \& Pieta, M. A. M. (2009a). Sentimento de gratidão em crianças de 5 a 12 anos. Psicologia em Estudo, 14(2), 243-250.

Freitas, L. B. de L., Silveira, P. G. \& Pieta, M. A. M. (2009b). Um estudo sobre o desenvolvimento da gratidão na infância. Revista Interamericana de Psicologíal Interamerican Journal of Psychology, 43(1), 49-56.

Godbout, J. T. (1999). O espírito da dádiva (P. C. F. X. Wuillaume, Trad.). Rio de Janeiro: Fundação Getúlio Vargas.

La Taille, Y. (2006a). A importância da generosidade no início da gênese da moralidade na criança. Psicologia: Reflexão e Crítica, 19(1), 9-17.

La Taille, Y. (2006b). Moral e ética: dimensóes intelectuais e afetivas. Porto Alegre: Artmed.

La Taille, Y. (2009). Formação ética: do tédio ao respeito de si. Porto Alegre: Artmed.

Menin, M. S. de S. (2000). Representaçôes sociais de justiça em adolescentes infratores: discutindo novas possibilidades de pesquisa. Psicologia: Reflexão e Crítica, 13(1), 59-71.

Müller, A. (2008). Educação em valores morais: o aprender e o ensinar sobre justiça. (Dissertação de Mestrado). Universidade Federal do Espírito Santo, Vitória.

Piaget, J. (1994). O juizo moral na criança. (2a ed.). (E. Leonardon, Trad.). São Paulo: Summus. [Trabalho original publicado em 1932].

Piaget, J. (2005). Introdução: problemas e métodos. In J. Piaget. A representação do mundo na criança (A. U. Sobral, Trad., pp. 9-31). Aparecida: Idéias e Letras. [Trabalho original publicado em 1926].

Pieta, M. A. M. \& Freitas, L. B. de L. (2009). Sobre a gratidão. Arquivos Brasileiros de Psicologia, 61(1), 100-108.

Resolução n. 196, de 10 de outubro 1996. (1996, 10 de outubro). Diretrizes e normas regulamentadoras de pesquisas envolvendo seres humanos. (1996). Diário Oficial da União, Brasília: Ministério da Saúde. Recuperado a partir de http://bvsms.saude.gov.br/bvs/saudelegis/cns/1996/res0196_10_10_1996. html.

Sales, E. da M. B. de. (2000). O conceito de justiça distributiva relacionado às normas sociais escolares. Psicologia: Reflexão e Crítica, 13(1), 49-58.

Sampaio, L. R., Camino, C. P. dos S. \& Roazzi, A. (2007). Justiça distributiva 
em crianças de 5 a 10 anos de idade. Psicologia: Reflexão e Crítica, 20(2), $197-$ 204.

Souza, R. M. de \& Ramires, V. R. R. (2006). Amor, casamento, familia, divórcio... e depois, segundo as crianças. São Paulo: Summus.

Tognetta, L. R. P. (2006). Sentimentos e virtudes: um estudo sobre a generosidade ligada às representaçôes de si. (Tese de Doutorado). Universidade de São Paulo,Instituto de Psicologia, São Paulo.

Tognetta, L. R. P. \& Assis, O. Z. M. (2006). A construção da solidariedade na escola: as virtudes, a razão e a afetividade. Educação e Pesquisa, 32(1), 49-66.

Vale, L. G. (2006). Desenvolvimento moral: a generosidade sob a ótica de crianças $e$ adolescentes. (Dissertação de Mestrado). Universidade Federal do Espírito Santo, Instituto de Psicologia, Vitória.

Vale, L. G. \& Alencar, H. M. (2008a). Generosidade versus interesse próprio: juízos morais de crianças e adolescentes. Psicologia: Teoria e Pesquisa, 24(4), 423-431.

Vale, L. G. \& Alencar, H. M. (2008b). Juízos morais de crianças e adolescentes sobre ausência de generosidade e punição. Revista de Psicologia da Vetor Editora, 9(2), 235-244.

Vale, L. G. \& Alencar, H. M. (2009). Generosidade para com amigo, desconhecido e inimigo: juízos morais de crianças e adolescentes. Interação em Psicologia, 13(2), 299-310. 